\title{
A Call to Action: \\ MOVING FORWARD WITH THE GOVERNANCE OF ARTIFICIAL INTELLIGENCE IN CANADA
}

\begin{abstract}
AVIV GAON $^{*}$ AND IAN STEDMAN ${ }^{* *}$
The Government of Canada has committed to accelerating the growth of the country's world-class artificial intelligence (AI) sector. This emerging technology has the potential to impact nearly every segment of Canada's economy, including national security, health care, and government services. To prepare for the key challenges and opportunities that AI will give rise to, we offer an innovative governance model for Canadian governments to adopt. This model recognizes the uncertainty ahead and prioritizes oversight and accountability while also encouraging a flexible policy-first approach. This approach fosters responsible AI innovation and supports Canada's emergence as a leader in AI technology and governance.
\end{abstract}

\section{TABLE OF CONTENTS}

I. INTRODUCTION . . . . . . . . . . . . . . . . . . . . . 1138

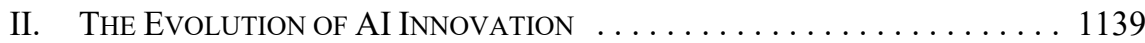

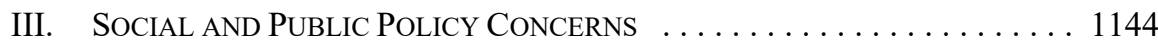

IV. OPPORTUNITIES FOR GOVERNMENT $\ldots \ldots \ldots \ldots \ldots \ldots \ldots \ldots \ldots \ldots \ldots$

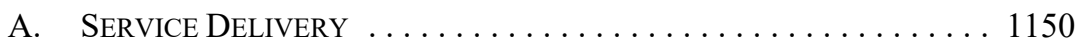

B. Social Health CARE $\ldots \ldots \ldots \ldots \ldots \ldots \ldots \ldots \ldots \ldots \ldots \ldots$

C. Democratic Institutions and Public Trust $\ldots \ldots \ldots \ldots \ldots . \ldots 1152$

D. ENVIRONMENTAL AND AgRiCUltural Justice . . . . . . . . . 1154

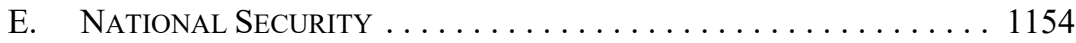

F. INTERNET ACCESS AND DATA COLLECTION . . . . . . . . . 1155

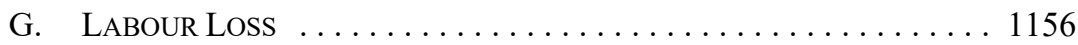

V. A Canadian Approach to a Global Challenge . . . . . . . . 1156

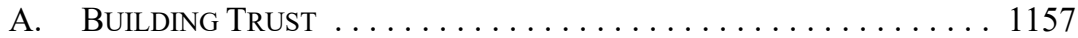

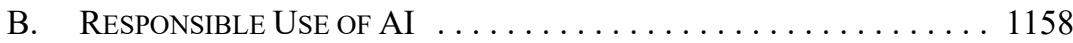

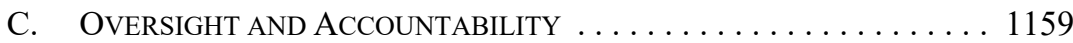

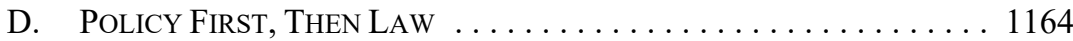

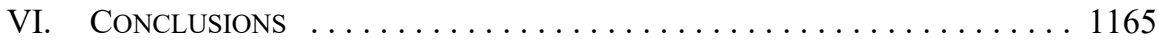

* Lecturer, the Interdisciplinary Center Herzliya, Israel, and PhD candidate, Osgoode Hall Law School. Fellow in Artificial Intelligence Law and Ethics at the Centre for Computational Medicine in Toronto's Hospital for Sick Children and $\mathrm{PhD}$ candidate, Osgoode Hall Law School. The authors are grateful to IP Osgoode, the law and technology program at Osgoode Hall Law School, and The Centre for Computational Medicine for their support of this research. We wish to thank Professor Giuseppina D'Agostino and Professor Maura Grossman for their thoughtful comments. We also wish to thank Justice Lorne Sossin, who has helped shape some of the ideas about parliamentary oversight during his supervision of Ian Stedman's doctoral work. Finally, we are incredibly grateful for the very thoughtful comments and suggestions made by the reviewers. Any mistakes are, of course, our own. 


\section{INTRODUCTION}

The way that humans interact with machines has long captivated writers. ${ }^{1}$ There is accordingly an extensive and wide-ranging literature that considers the implications of artificial intelligence (AI) in the fields of computer science, philosophy, economics, religion, ethics, and science fiction. ${ }^{2}$ Yet, as we have learned from the widespread adoption of the Internet and smartphones, we cannot fully predict the impacts of technology. Many of the concerns that preoccupy us in the early stages of a technology's adoption may in fact turn out to be trivial in the later stages. ${ }^{3}$

Developments in AI have stirred both interest in and concern about what lies ahead. Several authors have discussed the urgency with which we must think about prudent AI policy and have offered suggestions for regulatory changes that can minimize risks without thwarting innovation. Ryan Calo, ${ }^{4}$ Ian Kerr, ${ }^{5}$ Jean-Gabriel Castel, ${ }^{6}$ and other prominent scholars in the field have published papers calling on governments to develop policies in order to proactively address significant concerns that exist about the advancement of AI.

In this article, we will stay away from making ominous predictions about the future of AI and focus instead on current developments and the looming impact that AI will have on Canada as it becomes widely adopted. We will consider the policy areas to which Canadian governments (federal, provincial, and territorial) should turn their immediate attention and begin to steer their resources. There is so much to say about AI policy, however, that we must be attentive to the risk of saying nothing at all. We wish therefore to be clear upfront that we are only interested in accomplishing the modest goal of identifying key underanalyzed issues that are (and will be) of direct and specific interest to Canadians. We will do this by focusing on current affairs within Canada, both social and political.

See e.g. Nils J Nilsson, The Quest for Artificial Intelligence: A History of Ideas and Achievements (Cambridge: Cambridge University Press, 2010) at 3; Pamela McCorduck, Machines Who Think: A Personal Inquiry into the History and Prospects of Artificial Intelligence, 2nd ed (Natick, Mass: AK Peters, 2004) at 3-29 (both Nilsson and McCorduck provide a concise summary of the historical developments in the field of artificial intelligence); Aristotle, Politics, translated by Ernest Barker (New York: Oxford University Press, 1995) at 19 (planting the seeds for automation and human-machine relations); Patrick Lin, Ryan Jenkins \& Keith Abney, eds, Robot Ethics 2.0: From Autonomous Cars to Artificial Intelligence (New York: Oxford University Press, 2017); Nick Bostrom \& Eliezer Yudkowsky, "The Ethics of Artificial Intelligence" in Keith Frankish \& William M Ramsey, eds, The Cambridge Handbook of Artificial Intelligence (Cambridge: Cambridge University Press, 2014) 316 (addressing the many ethical challenges AI poses to society); Stuart J Russell \& Peter Norvig, eds, Artificial Intelligence: A Modern Approach, 3rd ed (Upper Saddle River, NJ: Pearson Education, 2010) at 1034-40 (for further reading on AI and ethics).

2 See e.g. Vincent C Müller, ed, Fundamental Issues of Artificial Intelligence (Switzerland: Springer International, 2016) (for a good overview on artificial intelligence in the areas of computer science, philosophy, cognition, and reasoning and ethics).

$3 \quad$ Jack B Balkin, "The Path of Robotics Law", (2015) 6 Cal L Rev Circuit 45 (the author argues at 47 that in 1991, for example, the World Wide Web's essential features were "its abilities to cross jurisdictional lines at will, to send digital information quickly and cheaply, and to facilitate anonymous communication." However, by 1999 "it was clearer that states could control features of Internet traffic and that the degree of truly anonymous communication the Internet afforded was overstated").

4 Ryan Calo, "Artificial Intelligence Policy: A Primer and Roadmap" (2017) 51:2 UC Davis L Rev 399 [Calo, "AI Policy"].

$5 \quad$ Ian Kerr \& Katie Szilagyi, "Evitable Conflicts, Inevitable Technologies? The Science and Fiction of Robotic Warfare and IHL" (2018) 14:1 L Culture \& Humanities 45.

6 J-G Castel \& Matthew E Castel, “The Road to Artificial Super-Intelligence: Has International Law a Role to Play?" (2016) 14:1 CJLT 1. 
We begin by providing a concise outline of AI innovation alongside an overview of several fields of AI technology that are poised to have an impact on Canadians. We draw attention to the positive implications of AI and to the federal government's commitment to AI innovation. In the third section, we consider some of the social concerns that AI technology could give rise to. We address several key issues that the government should prioritize, such as the risk posed by weaponized AI, concerns about data and privacy, how to respond to the inevitability of job loss, and the need to update Canada's intellectual property laws so that they can help support the growth of the country's AI industry. The fourth section of the article explores some of the specific opportunities that AI technology and advanced automation will give rise to for Canada. Key among those opportunities is the prospect of leveraging AI in order to improve health care (both service delivery and patient outcomes) and other government services. We look at the impact AI will have on democratic institutions and on Canada's national defence efforts. Finally, we emphasize the importance of public trust and making sure that AI is used responsibly. We propose a blended governance strategy for Canada that builds off the progress made in other countries and addresses Canada's AI challenge in an innovative yet unmistakably Canadian way. Our governance model is based on three pillars: education, private- and public-sector oversight, and access for Canadian parliamentarians to world-class experts in AI and emerging technology. The combination of these three pillars will allow Canada to maintain its status as a world leader not only in AI innovation but also in AI governance.

\section{The Evolution of AI InNOVAtion}

It is important to begin our exploration of the possible regulatory future of AI in Canada by first establishing what we mean by AI. The common denominator in all possible approaches to defining AI seems to be that the expression refers to computerized systems that simulate or enhance the cognitive capabilities of humans without constant and ongoing human input. ${ }^{7}$ What differentiates various conceptions of $\mathrm{AI}$ is the way in which particular systems are initially set up in order to go about accomplishing their "cognitive" work. ${ }^{8}$ In most cases, current AI systems require human input for their creation. Once operational, however, they become capable of performing calculations and solving complex problems without necessary ongoing human supervision.

An important distinction has been drawn between weak AI and strong AI. Weak AI refers to software programming that focuses on accomplishing a narrow and specific task. These programs simply assess their input(s) using a series of algorithms in order to provide results in well-defined domains (such as computer-assisted programs or tools). Strong AI is much more developed and refers to a machine that is programmed to perform at the same intellectual level as humans, if not greater. A strong AI system is sometimes referred to as artificial general intelligence because it is capable of acquiring new knowledge by programming itself with new data that it gathers through inputs. It can then use this new

See Russell \& Norvig, supra note 1 (for a discussion of eight different definitions of AI).

See generally Richard Bellman, An Introduction to Artificial Intelligence: Can Computers Think? (San Francisco: Boyd \& Fraser, 1978); Raymond Kurzweil, The Age of Intelligent Machines (Cambridge: MIT Press, 1990); Elaine Rich, Kevin Knight \& Shivashankar B Nair, Artificial Intelligence, 3rd ed (New Delhi: Tata McGraw-Hill, 2009). 
knowledge in order to increase its computational capacities (such as machine and deep learning capabilities).

A great deal of attention is being paid to strong AI precisely because of advancements in what is called "machine learning." If machines can be programmed to learn new information without ongoing human intervention, then, if left unchecked, they can theoretically evolve beyond their originally intended uses. The goal of this article is not to make an argument about what artificial intelligence is or whether it is good or bad but to draw attention to some of the opportunities and challenges that technological developments in this area are giving rise to for Canadian governments.

New applications of artificial intelligence technology are coming to the public's attention on a weekly basis. Discussions about AI are so pervasive, in fact, that many industry publications are hiring dedicated AI reporters. ${ }^{9}$ Algorithms that automate decision-making are being built into a wide variety of machines in almost every sector of commercial interest. Among these applications are self-driving cars, ${ }^{10}$ investment and finance, ${ }^{11}$ insurance services, ${ }^{12}$ medical research and diagnosis, ${ }^{13}$ civilian and military drones,${ }^{14}$ tools to conduct

See e.g. The New York Times, WIRED, The Register, and MIT Technology Review (all of which had dedicated AI reporters for at least some period of time during 2017). See especially Tom Simonite, a senior writer for WIRED in San Francisco covering artificial intelligence and its effects on the world ("Tom Simonite," WIRED, online: <https://www.wired.com/author/tom-simonite $>$ ) and Karen Hao, the artificial intelligence reporter for MIT Technology Review ("Karen Hao," MIT Technology Review, online: <https://www.technologyreview.com/profile/karen-hao/>). In particular, Hao covers the ethics and social impact of the technology as well as its applications for social good.

See generally Peter Stone et al, "Artificial Intelligence and Life in 2030 - One Hundred Year Study on Artificial Intelligence: Report of the 2015 Study Panel” (Stanford: Stanford University Press, 2016), online: <https://ai100.stanford.edu/2016-report> [100 Year Study]; Noah Zon \& Sara Ditta, "Robot, Take the Wheel: Public Policy for Automated Vehicles" (Toronto: The Mowat Centre, 2016); US Department of Transportation and the National Highway Traffic Safety Administration, Automated Driving Systems 2.0: A Vision for Safety (September 2017), online: <https://www.nhtsa.gov/sites/nhtsa. dot.gov/files/documents/13069a-ads2.0 090617 v9a tag.pdf>.

11 See e.g. Matt Turner, "Machine Learning is Now Used in Wall Street Dealmaking, and Bankers Should Probably Be Worried," Business Insider (4 April 2017), online: <https://www.businessinsider.com/ jpmorgan-using-machine-learning-in-investment-banking-2017-4>; Martin Arnold \& Laura Noonan, "Robots Enter Investment Banks' Trading Floors" Financial Times (6 July 2017), online: <https:// www.ft.com/content/da7e3ec2-6246-11e7-8814-0ac7eb84e5f1>.

12 See e.g. Anand Rao, Jamie Yoder \& Scott Busse, "AI in Insurance: Hype or Reality?" (PricewaterhouseCoopers, 2016), online: <https:/www.pwc.com/us/en/insurance/publications/assets/ pwc-top-issues-artificial-intelligence.pdf $>$ (According to PricewaterhouseCoopers' report, AI is expected to improve efficiencies via the greater automation of existing underwriting and claims processes).

13 See e.g. Daniel Akst, “Computers Turn Medical Sleuths and Identify Skin Cancer,” The Wall Street Journal (10 February 2017), online: $<$ https://www.wsj.com/articles/computers-turn-medical-sleuths-andidentify-skin-cancer-1486740634>; Alice Yan, "Dentists in China Successfully Used a Robot to Perform Implant Surgery Without Human Intervention,” Business Insider (21 September 2017), online: $<$ www.businessinsider.com/dentists-in-china-used-a-robot-to-perform-implant-surgery-2017-9>.

14 See e.g. Jacques Bughin et al, “Artificial Intelligence: The Next Frontier" (McKinsey Global Institute, 2017) at 29, 49, 56, online: $<$ https://www.projectfinance.pl/pluginfile.php/109/mod forum/attachment/ 487/MGI-Artificial-Intelligence-Discussion-paper.pdf $>$ (considers the impact that civilian drones will have on efficient product delivery, and also considers the implications of drones taking on timeconsuming and dangerous jobs, such as inspecting turbines and aircrafts); Bonnie Docherty, "Losing Humanity: The Case against Killer Robots" (Human Rights Watch, 2012), online: $<$ https://www.hrw. org/report/2012/11/19/losing-humanity/case-against-killer-robots $>$; Mary Ellen O'Connell, "Banning Autonomous Killing: The Legal and Ethical Requirement That Humans Make Near-Time Lethal Decisions" in Matthew Evangelista \& Henry Shue, eds, The American Way of Bombing: Changing Ethical and Legal Norms, From Flying Fortresses to Drones (Ithaca, NY: Cornell University Press, 2014) 224 at 224-34. 
complex legal research, ${ }^{15}$ home services,${ }^{16}$ programs that translate languages,${ }^{17}$ and programs that assist with making human resource decisions. ${ }^{18}$ Interesting uses for AI are also emerging in the fields of environmental and social justice, including helping to increase food production ${ }^{19}$ and assisting people who are confronted with physical and intellectual barriers. ${ }^{20}$ The potential uses of AI seem endless at this time.

The commercial advancement of AI technology has not been limited in its geographic reach either. While the United States is home to Silicon Valley and the headquarters for tech giants like Apple, Google, HP, Netflix, and Tesla, among others, interest in AI has taken hold across the globe. The People's Republic of China announced in July 2017 that it plans to upgrade its economy with AI as a main driving force. ${ }^{21}$ Russian President Vladimir Putin made his country's interest in AI clear when he announced that he believes "[a]rtificial intelligence is the future, not only for Russia, but for all humankind .... Whoever becomes the leader in this sphere will become the ruler of the world." ${ }^{22}$ Evidence suggests that interest

15 See e.g. Frank Pasquale \& Glyn Cashwell, "Four Futures of Legal Automation" (2015) 63 UCLA L Rev Discourse 26; Benjamin Alarie, Anthony Niblett \& Albert H Yoon, "How Artificial Intelligence Will Affect the Practice of Law" (2018) 68:1 UTLJ 106 (argues that AI use in the legal profession will improve access to justice and improve efficiency and transparency. They find the long-term impacts difficult to predict, however).

16 See 100 Year Study, supra note 10 at 24 (explores the idea that special purpose robots will deliver packages, clean offices, and enhance home security).

17 See e.g. Michal Ziemski, Marcin Junczys-Dowmunt \& Bruno Pouliquen, "The United Nations Parallel Corpus v1.0" (2016), online: <www.lrec-confi.org/proceedings/lrec2016/pdf/1195_Paper.pdf> (this paper was posted online alongside the release of the United Nations' Parallel Corpus. The Parallel Corpus is a collection of the UN's official records (in all six official languages of the UN) that cover the 25 years from 1990 to 2014 and are already in the public domain. The goal of the project described in the paper is to translate the Corpus into as many different languages as possible. Allowing access to the Corpus will allow the development of multilingual resources, encourage research, and encourage progress in various natural language processing tasks, such as machine translation).

18 See e.g. Stefan Strohmeier \& Franca Piazza, "Artificial Intelligence Techniques in Human Resource Management: A Conceptual Exploration" in Cengiz Kahraman \& Sezi Cevik Onar, eds, Intelligent Techniques in Engineering Management: Theory and Applications (Switzerland: Springer International, 2015) 149.

19 See e.g. MJ Aitkenhead et al, "Weed and Crop Discrimination Using Image Analysis and Artificial Intelligence Methods" (2003) 39:3 Computers \& Electronics in Agriculture 157; World Economic Forum, "Shaping the Future of Global Food Systems: A Scenarios Analysis" (January 2017), online: $<$ www3.weforum.org/docs/IP/2016/NVA/WEF FSA FutureofGlobalFoodSystems.pdf $>$ (argues that technology, including AI, "can create significant new value through innovations for food systems" at 22); Rob Trice, “Can Artificial Intelligence Help Feed The World?”Forbes (5 September 2017), online: $<$ https:/www.forbes.com/sites/themixingbowl/2017/09/05/can-artificial-intelligence-help-feed-theworld $>$ (discusses several ways that AI can improve agriculture, such as by automating harvesting and enabling image recognition in order to better detect pests that could negatively impact crop yield).

20 See e.g. Simon D’Alfonso et al, “Artificial Intelligence-Assisted Online Social Therapy for Youth Mental Health" (2017) 8 Frontiers in Psychology, online: <https://www.ncbi.nlm.nih.gov/pmc/ articles/PMC5454064>; Tom Simonite, "Machine Learning Opens Up New Ways to Help People with Disabilities," MIT Technology Review (23 March 2017), online: < https://www.technologyreview.com/ s/603899/machine-learning-opens-up-new-ways-to-help-disabled-people $>$.

21 The State Council, Press Release,"China Issues Guideline on Artificial Intelligence Development” (20 July 2017), online: <english.gov.cn/policies/latest_releases/2017/07/20/content_281475742458322. htm>.

22 "Whoever Leads in AI will Rule the World': Putin to Children on Knowledge Day," RT (1 September 2017), online: <https://www.rt.com/news/401731-ai-rule-world-putin>. 
in AI is also high in Japan, ${ }^{23}$ the United Kingdom, ${ }^{24}$ Singapore, ${ }^{25}$ Germany, ${ }^{26}$ Israel, ${ }^{27}$ and India. $^{28}$

Many countries have already begun to assemble advisory groups and committees in order to investigate and report to government about the potential of artificial intelligence. The United States government has published and sponsored several reports, including "Preparing for the Future of Artificial Intelligence," 29 "Artificial Intelligence, Automation, and the Economy," and "The Federal Big Data Research and Development Strategic Plan." "31 The Science and Technology Committee of the United Kingdom House of Commons has published a report called "Robotics and Artificial Intelligence." 32 Germany published its "Strategy for Automated and Connected Driving" ${ }^{33}$ and the European Parliament's Committee on Legal Affairs has published a "Report with Recommendations to the Commission on Civil Law Rules on Robotics." 34 These studies have all recognized that governments will need to gain expertise in artificial intelligence in order to attend properly to the needs of their nations' commercial industries and private citizens.

Sensing an opportunity, the federal government's 2017 and 2018 budgets emphasized Canada's strategic plan in the "digital future," committing \$125 million in its 2017 budget to launch a "Pan-Canadian Artificial Intelligence Strategy for research and talent," and \$1.7

Japan,The Headquarters for Japan's Economic Revitalization, New Robot Strategy: Vision, Strategy, Action Plan (Tokyo: Prime Minister's Office, 10 February 2015) (Japan has outlined a new robotic strategy indicating the need to develop international standards and security measures); see also Japan, Ministry of Economy, Trade and Industry, Press Release, "Robotics Policy Office is to be Established in METI" (1 July 2015), online: <www.meti.go.jp/english/press/2015/0701_01.html> (explaining that a Robotic Policy Office is to be established under the Ministry of Economy, Trade and Industry). UK, Science and Technology Committee, "Robotics and Artificial Intelligence," 5th Report of Sess 2016-17, (London: HC, 12 October 2016). See more recently UK, Select Committee on Artificial Intelligence, $A I$ in the UK: Ready, Willing and Able? (London: HL, 16 April 2018) at 15, online: $<$ https://publications.parliament.uk/pa/ld201719/ldselect/ldai/100/100.pdf >.

25 Sing, Prime Minister's Office, National Research Foundation, Press Release, “AI.SG: New National Programme to Catalyse, Synergise and Boost Singapore's Artificial Intelligence Capabilities" (3 May 2017), online: <https:/www.nrf.gov.sg/docs/default-source/modules/pressrelease/2017050314420821 91-press-release-(ai.pdf $>$ (the Singapore National Research Foundation will invest up to 150 million Singaporean dollars over the next five years into a new national program to enhance AI research in Singapore).

26 Germany, Federal Ministry of Transport and Digital Infrastructure, Strategy for Automated and Connected Driving (Berlin: Federal Ministry of Transport and Infrastructure, 2015) [Germany, Strategy]. The Science and Technology Committee at the Knesset (Israeli parliament) held a discussion on AI developments on 4 June 2018. Prior to the discussion, the Knesset's Research and Information Center published a special report on AI: Roy Goldsmith, "Information about AI" (Knesset Research and Information Center, 2018), online: $<$ https://fs.knesset.gov.il/globaldocs/MMM/eb0bf048-de5c-e811-80 e1-00155d0a9876/2_eb0bf048-de5c-e811-80e1-00155d0a9876_11_10863.pdf>.

28 In his 2018 budget speech, India's Minister of Finance mandated the National Institution for Transforming India (also known as Niti Aayog) to establish the AI National Program. In June 2018, Niti published its report outlining the role of the government in building an AI future: Anna Roy, "National Strategy for Artificial Intelligence: \#AIFORALL" (NITI Aayog, 2018), online: < niti.gov.in/writeread data/files/document publication/NationalStrategy-for-AI-Discussion-Paper.pdf $>$. US, Executive Office of the President, National Science and Technology Council Committee on Technology, Preparing for the Future of Artificial Intelligence (Washington, DC: 2016) [US, Preparing for $A I$.

30 US, Executive Office of the President, Artificial Intelligence, Automation, and the Economy (Washington, DC: 2016) [US, AI Automation].

31 US, The Networking and Information Technology Research and Development Program, The Federal Big Data Research and Development Strategic Plan (Washington, DC: 2016).

Supra note 24.

Supra note 26.

EC, Committee on Legal Affairs, Report with Recommendations to the Commissioner on Civil Law Rules on Robotics (Luxembourg: EC, 27 January 2017) [European Robotics]. 
billion over five years for research in the 2018 budget. ${ }^{35}$ The task of managing these funds has been assigned to the Canadian Institute for Advanced Research (CIFAR), which has implemented a Strategy to promote collaboration between Canada's main centres of expertise in Montreal, Toronto-Waterloo, and Edmonton. ${ }^{36}$ Other institutions across Canada have also dedicated resources, establishing committees and task forces in order to address AI challenges and concerns. York University, for example, has formed an "AI and Society Task Force," with a goal of generating "recommendations towards how York University can advance research and take advantage of research, scholarship and academic opportunities in this area." ${ }^{37}$

Indeed, the ultimate goal is to effectively position Canada as a world leader and destination of choice for companies and academics looking to invest in artificial intelligence and innovation. ${ }^{38}$ To do this, a robust plan similar to the United States' Strategic Plan will almost certainly have to be in place. ${ }^{39}$ The US Plan establishes a set of objectives and recommendations for federally-funded AI research, both occurring within and outside of government. The aim is to produce new "AI knowledge and technologies that provide a range of positive benefits to society, while minimizing the negative impacts. ${ }^{~}{ }^{40}$ Canada must quickly undertake a similar study in order to set out its vision for the future of AI.

A Canadian plan should, among other things, address how technological advancements are expected to impact the workforce. Layoffs of skilled workers may in fact already be underway in the automotive industry, ${ }^{41}$ and the advancement of AI could continue to accelerate the pace of change. From an innovation policy perspective, the government could look to mitigate some of the expected employment displacement by opening new markets driven by AI technologies. While there may be no short-term solutions to these challenges, the country's strong education system could prove useful in helping it to champion innovative policies and programs, if and when they are put in place.

The federal government's commitment to artificial intelligence research and innovation has already begun to pay dividends for the technology sector. A number of transformative AI companies have either emerged or opened Canadian offices, including Element AI, Integrate AI, ROSS Intelligence, Google's DeepMind research lab, and Uber's self-driving car research group, among many others. Optimism is high that the industry will continue to

Canada, Department of Finance, \#Budget2017: Building a Strong Middle Class (Ottawa: Department of Finance, 2017) at 104 [Budget 2017] (the 2018 budget reinforces Canada's commitment to AI research). See also Canada, Department of Finance, Equality + Growth: A Strong Middle Class (Ottawa: Department of Finance, 2018) at 85, 92-94, online: <https://budget.gc.ca/2018/docs/plan/budget-2018en.pdf>.

36 CIFAR, "Pan-Canadian Artificial Intelligence Strategy," online: <https://www.cifar.ca/ai/pan-canadianartificial-intelligence-strategy>.

37 York University, News Release, "IP Osgoode Researchers Join York University's Artificial Intelligence and Society Task Force" (18 November 2018), online: <https://yfile.news.yorku.ca/2018/11/18/iposgoode-researchers-join-york-universitys-artificial-intelligence-and-society-task-force> .

38 Budget 2017, supra note 35 at 103-107.

39 US, National Science and Technology Council, Networking and Information Technology Research and Development Subcommittee, The National Artificial Intelligence Research and Development Strategic Plan (Washington, DC: 2016) [US, Strategic Plan].

$40 \quad$ Ibid at 3

$41 \quad$ Bruce Campion-Smith, "GM Tells Ottawa, Queen's Park that Oshawa Assembly Plant Will Definitely Close," The Star (15 January 2019), online: <https://www.thestar.com/politics/federal/2019/01/15/gmtells-ottawa-queens-park-that-oshawa-assembly-plant-will-definitely-close.html>. 
grow as CIFAR and Toronto's Vector Institute work to broaden their reach in this space. ${ }^{42}$ There is therefore good reason to begin thinking about what challenges and opportunities lie ahead for Canadian governments with respect to their oversight and governance of this exciting new sector.

\section{Social And Public Policy Concerns}

Innovation can bring complication with it, which is exactly what we see as new applications of AI emerge. Regardless, provincial and territorial governments are not hesitating to invest, ${ }^{43}$ and it is becoming increasingly more important for legislators to start considering the role that law and policy must play in balancing the public good against private interests. This section of the article will outline some of the more salient and pressing challenges that have come to the fore during the steady ascent of AI and machine learning.

Canadian scholars, among others, have expressed a great deal of concern about the potential for AI-controlled machines to injure or kill sentient beings. ${ }^{44}$ Clear examples of these concerns can be found in the literature related to self-driving cars and weaponized or militarized drones. ${ }^{45}$ It is also reasonable to think that intelligent machines could cause harm to people in manufacturing settings and healthcare settings, and when used in environmental management. Equally as troublesome is the fact that AI has actually been used by judges in order to assist with sentencing decisions. ${ }^{46}$ Each of these uses and scenarios give rise to questions about what social and moral values are being programmed into the algorithms that make up the control centre of the AI technology being deployed. This also gives rise to questions about how we ought to respond when AI causes harm to humans, a discussion that is beyond the scope of this article.

Along with the concerns about the potential for intelligent machines to cause physical harm, there is also a growing body of literature addressing the implications of AI systems being programmed with biased algorithms. ${ }^{47}$ Not only can biases be incidentally or accidentally inputted into AI systems by their original programmers, but they can also be

42 See Vector Institute, “Our Vision,” online: <https://s3.ca-central-1.amazonaws.com/vectorinstitute.ai/ resources/v2/Vector_Institute_Vision_Mission.pdf $>$ (the Institute is an independent, not-for-profit corporation whose vision is to "drive excellence and leadership in Canada's knowledge, creation, and use of artificial intelligence (AI) to foster economic growth and improve the lives of Canadians").

43 Ontario, Office of the Premier, News Release, "Québec and Ontario Working Together to Fuel Innovation and Growth," (22 September 2017), online: $<$ https://news. ontario.ca/opo/en/2017/9/quebecand-ontario-working-together-to-fuel-innovation-and-growth.html $>$ (in which Quebec announced a $\$ 100$ million commitment to AI over the next five years and Ontario reaffirmed its $\$ 50$ million commitment to AI through the Vector Institute).

$44 \quad$ See e.g. Ian Kerr, "Weaponized AI Would Have Deadly, Catastrophic Consequences. Where Will Canada Side?" The Globe and Mail (6 November 2017), online: <https://www.theglobeandmail. com/opinion/weaponized-ai-would-have-deadly-catastrophic-consequences-where-will-canadaside/article36841036/ $>$ (the article draws attention to the fact that a large group of highly respected Canadian scholars have called on the Prime Minister of Canada to issue a ban on weaponized AI).

45 Heather M Roff \& Richard Moyes, "Meaningful Human Control, Artificial Intelligence and Autonomous Weapons" (Briefing Paper for the Meeting of Experts on Lethal Autonomous Weapons Systems (LAWS), UN Convention on Certain Conventional Weapons, April 2016), online: <www. article36.org/wp-content/uploads/2016/04/MHC-AI-and-AWS-Final.pdf>.

46 Andrea Roth, "Trial by Machine" (2016) 104:5 Geo LJ 1245.

47 Amanda Levendowski, "How Copyright Law Can Fix Artificial Intelligence's Implicit Bias Problem" (2018) 93:2 Wash L Rev 579. 
learned as a result of the conventions in the language used to program ${ }^{48}$ or learned by systems that are capable of acquiring and using new data. ${ }^{49}$ As Google has helpfully acknowledged in a video the company uploaded to YouTube, there is the potential for interaction bias, latent bias, and selection bias. ${ }^{50}$ Interaction bias arises when a user biases an $\mathrm{AI}$ as a result of their interactions with it (for example, if the user is asked to draw a shoe in order to teach the machine what a shoe looks like and they choose to only draw men's shoes, never women's shoes). Latent bias exists when an algorithm simply includes incorrect correlations, such as would exist if it were programmed to believe that all veterinarians are women. Selection bias exists when the data being used to train the algorithm includes an over-representation of certain populations (for example, when facial recognition software has been created using a disproportionately high number of Caucasian faces). ${ }^{51}$

AI is also being developed to perform the jobs of people who have undergone years of training and certification. For example, certain manufacturing processes that were once undertaken by licensed and trained operators can now be controlled by AI, legal research is being done by $\mathrm{AI},{ }^{52}$ medical diagnostics are evolving through AI (especially with respect to the identification of genetic diseases), and weaponized drones for military use, complex accounting, and even driverless vehicles involve AI. These are areas of human life that we have heretofore generally believed to require a degree of intellectual judgment and acuity that made them resistant to automation. It can be very important for an individual to have empathy for others when exercising his or her professional judgment, but this may prove to be a difficult task for even the most advanced of machines. Regardless, it seems inevitable that AI will soon be deployed in situations where human empathy and high levels of judgment have historically been deemed necessary.

Another challenge that must be addressed is the availability of data. Data is the fuel for machine learning and AI development, but it also poses a significant risk to our privacy and is open to manipulation. For example, deploying AI-based technology to improve safety in public spaces within cities will have both positive and negative implications. AI and machine learning could be used to control surveillance cameras that might (at least in theory) deter crime or, through pattern recognition, improve the chances of its early detection. This surveillance technology could detect whether someone is expressing aggressive or otherwise odd behavior and could dispatch peace officers in order to monitor the situation more directly. This could be seen as a positive development for those who are concerned about safety (business owners in neighbourhoods with high crime rates, for example), but it could

Aylin Caliskan, Joanna J Bryson \& Arvind Narayanan, "Semantics Derived Automatically From Language Corpora Contain Human-Like Biases," (2017) 356:6334 Science 183, online: $<$ https://research portal.bath.ac.uk/en/publications/semantics-derived-automatically-from-language-corpora-necessarily>. See e.g MJ Wolf, K Miller \& FS Grodzinsky, "Why We Should Have Seen That Coming: Comments on Microsoft's Tay 'Experiment', and Wider Implications" 47:3 ACM Computers \& Society 54 (argues that developers of learning software have greater ethical responsibilities when their software interacts directly or indirectly with people (for example, via social media)).

50 Google, "Machine Learning and Human Bias" (25 August 2017), online: YouTube <https://www. youtube.com/watch? $\mathrm{v}=59 \mathrm{bMh} 59 \mathrm{JQDo}>$.

51 Clare Garvie \& Jonathan Frankle, "Facial-Recognition Software Might Have a Racial Bias Problem," The Atlantic (7 April 2016), online: <https://www.theatlantic.com/technology/archive/2016/04/theunderlying-bias-of-facial-recognition-systems/476991> (algorithms developed in the United States, France, and Germany were better at recognizing Caucasian facial characteristics than those of other races).

$52 \quad$ See e.g. supra note 15. 
also be seen as a huge incursion on personal privacy. As Stanford's 100 Year Study has pointed out, "AI may become overbearing or pervasive in some contexts." careful, we may lose what little privacy we have left and become "naked" to the world. For this reason, Ann Cavoukian has argued in her work on "AI Ethics by Design" that our AIrelated policies must respect privacy as being a fundamental right before we can responsibly move forward. ${ }^{54}$

One of the many excellent reasons to want to move forward with using AI is that it may actually be able to help us minimize the risks of bias toward minority groups in Canada. ${ }^{55} \mathrm{AI}$ technology could be used in place of human decision-makers in situations where bias has been persistent in the past. This could help improve and promote the important Canadian value of fairness. It may in fact be counterproductive to feel threatened by the technological progress that AI represents when we could instead dream big about what lies ahead and proceed with a cautious optimism. Unfortunately, in our opinion, the recent treatment of technological innovation in other jurisdictions has not proven as accommodating of AI as it should. As we will explore throughout this article, several policies in the EU and the US seem to work against the development of AI and would not translate well into the Canadian context.

Before looking specifically at the Canadian context, however, it is important to first acknowledge that we live in an increasingly connected world and that the implications of this fact are undoubtedly far from trivial and extend well beyond privacy concerns. Cellular phone and social media use are widespread, televisions have become "smart," and not only do our vehicles have GPS tracking but so too do our watches. More importantly, most households have computers with access to the Internet. ${ }^{56}$ Internet users are being tracked through their cellular devices and by "cookies" that are left on their computers by websites that they visit. These cookies are controlled by private companies and collect information about the user's actions and preferences as they surf the web. Private companies trade and sell these data with one another and use it to create user profiles and target advertising to specific users. Algorithms are used to determine which data to collect and then to analyze those data in order to determine what advertising to show or deals to offer to each Internet user. Income is earned for the algorithm's creator by maximizing the number of mouse clicks on a particular link. Social media websites, search engines, personal finance companies, governments, car manufacturers, and so on, are all collecting data and creating huge databases that they can use for their own purposes. ${ }^{57}$

53 Stone et al, supra note 10 at 36.

Ann Cavoukian, "AI Ethics by Design,” online: Ryerson University $<$ https://www.ryerson.ca/content/ dam/pbdce/papers/AI_Ethics_by_Design.docx>.

55 See e.g. US, Executive Office of the President, Big Data: AReport on Algorithmic Systems, Opportunity, and Civil Rights (Washington, DC: 2016).

56 Canadian Radio-television and Telecommunications Commission, Communications Monitoring Report 2016, Section 2.0: Canada's Communication System: An Overview for Canadians (Ottawa: Canadian Radio-television and Telecommunications Commission, 2016), online: <https://www.crtc.gc.ca/eng/ publications/reports/PolicyMonitoring/2016/cmr2.pdf $>$ at 23 (84.9 out of 100 Canadian households report having Internet access from the home).

57 See e.g. Paul Przemysław Polański, "Some Thoughts on Data Portability in the Aftermath of the Cambridge Analytica Scandal" (2018) 7:4 J European Consumer \& Market L 141 (what has come to be known as the Facebook-Cambridge Analytica scandal is a vivid example of the harmful impact that data harvesting can have on personal privacy. Cambridge Analytica used Facebook users' profile information without their consent in order to manipulate users' opinions about political issues). 
The OECD Competition Committee has expressed concern that these usages of data could create an anti-competitive environment that manipulates consumers. A committee report notes that there are disruptive data-related innovations in many sectors and that we must recognize "the risks of consumer harm in the absence of an adequate competition framework that disciplines these new market realities." 58 In the digital age, for example, colluding between competitors might become very easy. Algorithms can be used to change prices so that they match closely with competitors' prices or to cause the supply of certain products to lower in order to drive a surge in price. The development of new ways to manipulate the market will have both good and bad consequences for consumers. One positive, at least in theory, is that consumers may be able to leverage these same tools in order to make better decisions about when and what to purchase (airline fare change alerts, for example). Unfortunately, if we do not also regulate the use of algorithms by vendors, then this will doubtless have the effect of "limiting consumer choice and autonomy; increasing consumers" vulnerability to inefficient decisions made on their behalf and to cyber-security harms; and creating negative psychological and social implications." 59

Canada's Competition Bureau is attentive to these concerns. The Competition Commissioner published a Draft Discussion Paper that echoes several of the apprehensions raised by the OECD and other countries. ${ }^{60}$ In the report, the Commissioner expresses concern about the use of big data to facilitate anti-competitive behavior that could enable cartels and deceptive marketing policies. The Commissioner remarks that "[d]ata are increasingly becoming a critical input in certain markets and may serve as a significant barrier to entry or expansion. In certain cases, access to and control over critical data that serve as an essential input may confer market power." ${ }^{\prime 61}$ Further, "[a]ccess by firms to certain data about their competitors may increase their ability to coordinate their behaviour with each other. Firms can analyze data about their competitors to gain insight into the actions that they have taken and into the strategies that led to those actions." ${ }^{\circ 2}$ When data combine with highly advanced algorithms that can analyze markets and make decisions in order to change prices and supply, cartel pricing can be expected. Interestingly, the Competition Commissioner also noted that using algorithms and big data to coordinate prices may not necessarily constitute an offence under the Competition Act, ${ }^{63}$ since a cartel offense requires proof that an agreement has been reached between competitors. ${ }^{64}$

$<$ www.oecd.org/competition/algorithms-collusion-competition-policy-in-the-digital-age.htm>.

Michal S Gal \& Niva Elkin-Koren, "Algorithmic Consumers" (2017) 30:2 Harv JL \& Tech 309 at 322.

See also generally Michal S Gal, "Algorithmic Challenges to Autonomous Choice" Mich Telecomm \& Tech L Rev [forthcoming], online: <https://papers.ssrn.com/sol3/papers.cfm?abstract_id= 2971456>; Salil K Mehra, "Antitrust and the Robo-Seller: Competition in the Time of Algorithms" (2016) 100:4 Minn L Rev 1323.

Competition Bureau, Big Data and Innovation: Implications for Competition Policy in Canada, (Gatineau: Competition Bureau, 2017) at 8-9, online: <www.competitionbureau.gc. ca/eic/site/cbbc.nsf/vwapj/Big-Data-e.pdf/\$file/Big-Data-e.pdf>.

Ibid at 15 .

Ibid at 20 .

RSC 1985, c C-34, Part VI (this does not preclude the possibility of civil proceedings, however). Competition Bureau, supra note 60 at 20. 
The European Union recognized the many risks of big data collection when it passed the General Data Protection Regulation (GDPR) in 2016. ${ }^{65}$ The GDPR regulates the treatment of any data that originate in the EU and affects many businesses, services, goods, and marketing both within the EU and abroad, including Canada. The GDPR has clear implications for the collection of data and may possibly pose a global challenge for the advancement of machine learning, although it is still too soon to tell. Privacy is of course an important concern in the new technological era, but data are the basis for future developments and extensive regulation in this field might significantly slow innovation. ${ }^{66}$

There is notable anxiety about the recent changes. For example, the GDPR forces companies to explain their algorithms and their AI methods. ${ }^{67}$ This may lead to challenges because it is not always possible to explain how algorithms and AI make specific choices. Machine learning systems, as we have explained above, are designed to process information on their own in order to develop new methods and approaches for accomplishing a given task. The drafters of the GDPR no doubt understood this and have chosen to attempt to drastically reshape the heretofore expected trajectory of the evolution of machine learning systems. ${ }^{68}$ As with other concerns, Canada ought to approach the challenge of big data in a way that is more deliberately attentive to the advancement of machine learning technologies. How this should look remains a matter about which there must be extensive public discussion.

Artificial intelligence also presents a challenge to Canada's intellectual property laws in relation to both the data inputs necessary for AI and the outputs generated by AI (for example, the creations or inventions). In fact, the current laws in Canada might hinder the progress of AI. As has been reported regarding the country's patent laws, "[ $\mathrm{t}]$ he track record in Canada so far is not promising. Out of the 100 or so patents related to machine learning that have been developed in Canada over the past 10 years, more than half have ended up in the hands of foreign companies such as Microsoft and IBM. ${ }^{\circ 9}$ Ryan Abbott has helpfully explained this same challenge in the context of US patent law. Abbott explains that "the Patent Act requires that inventors be 'individuals," which is likely supposed "to reflect the constitutional language that specifically gives 'inventors' the right to their discoveries as opposed to other legal entities that might assert ownership rights." ${ }^{70}$ Computer programs are therefore producing outputs that could in theory result in patents but which are not patentable since humans are not directly involved in the creation of those outputs. Abbott further notes that "patent law jurisprudence requires that inventions be the result of a 'mental act.",71

65 EC, Regulation (EU) 2016/679 of the European Parliament and of the Council of 27 April 2016 on the Protection of Natural Persons with Regard to the Processing of Personal Data and on the Free Movement of Such Data, and repealing Directive 95/46/EC (General Data Protection Regulation), [2016] OJ, L 119/1 [GDPR] (it replaced the 1995 Data Protection Directive (DPD) and came into force in May 2018).

66 Tal Z Zarsky, "Incompatible: The GDPR in the Age of Big Data" (2017) 47:4 Seton Hall L Rev 995 at 996.

67 GDPR, supra note 65, art 14.

68 Sandra Wachter, Brent Mittelstadt \& Chris Russell, "Counterfactual Explanations Without Opening the Black Box: Automated Decisions and the GDPR" (2018) 31:2 Harv JL \& Tech 841 (argues that "[t]he GDPR itself provides little insight into the intended purpose and content of explanations" at 880).

69 Joe Castaldo, "Why Does Canada Give Away its Best Ideas in AI?" Maclean's (13 April 2017), online: $<$ www.macleans.ca/politics/ottawa/why-does-canada-give-away-its-best-ideas-in-ai>.

Ryan Abbott, "I Think, Therefore I Invent: Creative Computers and the Future of Patent Law" (2016) 57:4 Boston College L Rev 1079 at 1096-97.

Ibid at 1097 . 
Computers are not persons under the law, and they cannot therefore possess mental capacity. The Canadian Patent $A c t^{72}$ mirrors the US law by effectively preventing computer programs from being considered inventors. ${ }^{73}$ Although the term "inventor" is not defined in the Patent Act, a patentee "means the person for the time being entitled to the benefit of a patent." It is implicitly clear that a Canadian inventor must be a human. ${ }^{75}$ The Patent Act's deficiencies could steer Canadian programmers towards spending their time trying to create patentable programs rather than committing themselves fully to developing AI that has the ability to learn and create on its own. Canada's intellectual property regime will be confronted with these important considerations as AI advances.

AIs and computer-generated works might also face copyright and authorship challenges, given that there might not be a human author involved in the creation of the AI's work. In a manner similar to its patent laws, Canada's copyright laws protect human authors. In the case of AI, this might be the programmer of the AI or the user of the program. ${ }^{76}$ Other scholars argue that an AI's work should not be considered a copyrighted work at all; in other words, it should be considered "authorless." "77 Obviously, these concerns must be addressed as part of Canada's IP-AI policy.

Further challenges may also arise as a result of the fair dealing provisions in the Copyright Act. ${ }^{78}$ The Act allows the use of copyrightable material for non-commercial purposes such as education, study, and research, but not for commercial purposes. In order to work, however, machine learning relies on the availability of important and valuable data such as that which the Act seeks to protect. A program that is mining data (perhaps in order to ensure that it has balanced and unbiased inputs) might therefore also be committing copyright infringement. If the federal government wants to be a leader in AI, then a new approach to fair dealing must be considered..$^{79}$ If not, there will almost certainly be many legal challenges claiming that authors' rights are being infringed by AI systems using copywritten data without permission. It seems, however, that the federal government is moving in the right direction in attempting to devise a more coherent data policy in order to address data barriers and other concerns that we have pointed out. Several companies, scholars, and industry

RSC 1985, c P-4.

Abbott, supra note 70 at 1103 .

Supra note 72 , s 2.

David Vaver, Intellectual Property Law: Copyright, Patents, Trade-marks, 2nd ed (Toronto: Irwin Law, 2011) at 363-64.

76 Pamela Samuelson, “Allocating Ownership Rights in Computer-Generated Works” (1986) 47 U Pitt L Rev 1185; Annemarie Bridy, "Coding Creativity: Copyright and the Artificially Intelligent Author" [2012] Stan Tech L Rev 1. See also Emily Dorotheou, "Reap the Benefits and Avoid the Legal Uncertainty: Who Owns the Creations of Artificial Intelligence?" (2015) 21:4 Computer \& Telecommunications L Rev 85.

77 Jane C Ginsburg \& Luke Ali Budiardjo, “Authors and Machines” (2018) 34:2 BTLJ [forthcoming in 2019] at 8; James Grimmelmann, "There's No Such Thing as a Computer-Authored Work - And It's a Good Thing, Too" (2016) 39 Colum JL \& Arts 403 at 414.

RSC 1985, c C-42, s 29.

See Giuseppina D’Agostino, “Healing Fair Dealing? A Comparative Copyright Analysis of Canada's Fair Dealing to UK Fair Dealing and US Fair Use" (2008) 53:2 McGill LJ 309 (the author provides a thorough review of fair dealing and offers several suggestions to remedy the fair dealing exemption in Canada). 
leaders have even advocated for amending the Copyright Act to include either a broader fair dealing doctrine or an exemption for AI. ${ }^{80}$

Despite all the challenges facing government in relation to the country's intellectual property laws, the biggest challenge may simply be that AI is still in its infancy. We already have a good sense of the many ways that AI can and will be used, but we also know that AI has the potential to be a key player in future technological innovations that have not even been conceived of yet. Governments would be foolish not to ask how they can better prepare themselves for the unfamiliar future that lies ahead. However, ensuring that innovation does not outpace regulatory preparation to the detriment of the population is not a new challenge. Governments call standing committees, conduct public consultations, and create expert advisory panels all the time in order to address emerging and evolving issues. Artificial intelligence certainly presents an important challenge, but it is not one that governments should be immobilized by. Machines are not poised to take over the world so imminently that governments no longer have time to prepare. ${ }^{81}$

\section{OPPORTUNITIES FOR GOVERNMENT}

Regardless of the challenges that we have drawn attention to above, Canada's government stands to benefit a great deal from the advancement of AI. This section of the article addresses some of the opportunities that $\mathrm{AI}$ is giving rise to.

\section{A. SERVICE DELIVERY}

Employees who provide government services, such as at passport offices or immigration offices, make decisions on individual files based on policies and procedures that they have been trained to apply. It may take several days, weeks, or months for a human worker to assess an application once it is filed. As that file is being processed, the government employee (who is most often unionized) will have to balance the demands of processing that file with the demands of processing other files and will have to do so during regular business hours. An AI machine, on the other hand, can be programmed with and learn policies, procedures, and precedents at any time of day, is not unionized, and will not file a grievance if it is asked to work evenings and weekends. Canada's government, which is estimated to

See e.g. Pina d'Agostino, "Submission to the Standing Committee on Industry, Science and Technology for the Statutory Review of the Copyright Act" (IP Osgoode, 2018), online: <www.ourcommons.ca/ Content/Committee/421/INDU/Brief/BR10269431/br-external/DagostinoGiuseppina-e.pdf>; Microsoft, "Submission of Microsoft to the Standing Committee on Industry, Science and Technology on the 2018 Statutory Review of the Copyright Act" (Microsoft, 2018) at 7, online: <www.ourcommons.ca/ Content/Committee/421/INDU/Brief/BR10008894/br-external/MicrosoftCanada-e.pdf $>$. Others have supported a broader fair dealing doctrine, see e.g. Pascale Chapdelaine et al, "Brief-Statutory Review of the Copyright Act submitted by Pascale Chapdelaine, on behalf of Canadian intellectual property law scholars" (2018), online: <www.ourcommons.ca/Content/Committee/421/INDU/Brief/BR10166923/brexternal/ChapdelainePascale01-e.pdf $>$.

81 See e.g. Erik Sofge, "Why Artificial Intelligence Will Not Obliterate Humanity: It's Not Smart Enough to Turn Sinister," Popular Science (19 March 2015), online: <www.popsci.com/why-artificialintelligence-will-not-obliterate-humanity>; Michael Shermer, "Artificial Intelligence Is Not a ThreatYet," Scientific American (1 March 2017), online: <https://www.scientificamerican.com/article/ artificial-intelligence-is-not-a-threat-mdash-yet>. 
have a debt greater than $\$ 600$ billion, ${ }^{82}$ arguably has an obligation to explore cost reduction opportunities in its service delivery models, and leveraging AI presents one such opportunity. These technologies must not be deployed without extensive testing, however, as was made clear by a poignant report from Petra Molnar and Lex Gill that was published in 2018. ${ }^{83}$

The Treasury Board of Canada Secretariat (TBS) has recognized this obligation to explore how AI can improve service delivery and has prepared a policy paper on the subject. The TBS engaged in extensive public consultations throughout the research stages of its project and even Tweeted ${ }^{84}$ and blogged ${ }^{85}$ about the paper's progress. The report's author, Michael Karlin, has sought input from academic, industry, and government experts throughout the writing process, and invited co-creation from the online community by posting drafts of the white paper on a designated government website called "GC Collab." collaborative process has also been used to develop algorithmic impact assessment tools. ${ }^{87}$ Governments across the country will no doubt be able to benefit from the excellent work that is being done at the federal level.

\section{B. Social Health Care}

Health care in Canada is delivered through a system that is publicly funded. As such, health care spending "is the single largest budget item for every province in Canada, ranging from 34.3 percent of total program spending in Quebec to 43.2 percent in Ontario in 2016." ${ }^{\circ 8}$ This is important to draw attention to because AI has the potential to transform health care by improving diagnosis and treatment, especially of genetic diseases both common and rare. ${ }^{89}$ Canada passed the Genetic Non-Discrimination $A c t^{90}$ in 2017 with the understanding that genetic testing is becoming a hugely important part of health care. AI systems have the ability to improve diagnosis by comparing large numbers of genomic data sets to one another. This comparison can reveal matching abnormalities in the genomes of different people who have similar phenotypic manifestations of disease. AI can also be used to help diagnose disease through visual learning, such as via a cellphone camera or other optical

The Canadian Press, “Canada Posts \$17.8 Billion Federal Deficit in 2016-17,” BNN Bloomberg (19 September 2017), online: $<$ https://www.bnnbloomberg.ca/canada-posts-17-8-billion-federal-deficit-in2016-17-1.860399> (in which it is noted that the debt was $\$ 631.9$ billion at 31 March 2017). Petra Molnar \& Lex Gill, "Bots at the Gate: A Human Rights Analysis of Automated Decision-Making in Canada's Immigration and Refugee System," (Toronto: The Citizen Lab \& University of Toronto Faculty of Law International Human Rights Program, 2018), online: <https://ihrp.law.utoronto.ca/ sites/default/files/media/IHRP-Automated-Systems-Report-Web.pdf>.

Michael Karlin, online: Twitter $<$ https://twitter.com/supergovernance>.

Michael Karlin, Supergovernance (blog), online: $<$ https://medium.com/@supergovernance>.

Government of Canada, "GCcollab," online: <https://gccollab.ca $>$ (a website that is designed to facilitate collaboration and that is open to anyone, by invitation).

Michael Karlin, "A Canadian Algorithmic Impact Assessment” (18 March 2018) Supergovernance (blog), online: <https://medium.com/@supergovernance/a-canadian-algorithmic-impact-assessment$128 \mathrm{a} 2 \mathrm{~b} 2 \mathrm{e} 7 \mathrm{f} 85>$.

88 Bacchus Barua, Milagros Palacios \& Joel Emes, "The Sustainability of Health Care Spending in Canada 2017" (Fraser Institute, 2017) at i, online: < https://www.fraserinstitute.org/sites/default/files/sustain ability-of-health-care-spending-in-canada-2017.pdf $>$.

89 See e.g. Nadine Bakkar et al, "Artificial Intelligence in Neurodegenerative Disease Research: Use of IBM Watson to Identify Additional RNA Binding Proteins Altered in Amytrophic Lateral Sclerosis," (2018) 135:2 Acta Neuropathol 227, online: <https://link.springer.com/content/pdf/10.1007\%2Fs00401017-1785-8.pdf>.

$90 \quad$ SC 2017, c 3 . 
device. ${ }^{91}$ Identifying these abnormalities earlier leads to diagnosis and treatment and can also help to spur the development of targeted therapies.

Our ability to analyze and understand the human genome is allowing personalized or targeted medicine to become the new norm. Consider also the impact that the emergence of safer and more accurate genome editing techniques, such as CRISPR-Cas9, is already having on science and medicine. ${ }^{92}$ Couple this with what many hope will be a renewed emphasis on basic science research in light of the recommendations of Canada's 2017 report on Federal Support for Fundamental Science, ${ }^{93}$ and the future looks promising. Hospitals are also launching high performance computing labs, such as the Centre for Computational Medicine at Toronto's Hospital for Sick Children, in order to begin to harness big data and machine learning. Advancements in this space will undoubtedly improve service delivery and patient outcomes, while also reducing costs.

\section{Democratic Institutions And Public Trust}

Canada is generally regarded as one of the world's leading democracies. This is believed to be the case because Canada has developed systems and rules to help strengthen and protect democratic values and democratic institutions. For example, Canada has rules about fairness in elections that are administered by a dedicated Commissioner of Parliament. There are also access to information and privacy laws, conflict of interest laws, and an Auditor General who conducts value-for-money financial audits of government spending. Despite its generally strong reputation for protecting its democratic institutions and values, however, Canada has also lived through a few challenges that demonstrate the impact AI can have on institutions dedicated to advancing public trust in government.

Controversy befell Canada's 2011 general election when allegations were made that voters were receiving robocalls with incorrect information that was calculated to suppress their vote. Simple machines running relatively simple programs made telephone calls to voters in order to direct them to the wrong voting stations. ${ }^{94}$ This was not an AI issue per se, but it does give rise to concerns about the impact that machines can have on electoral systems. It is also entirely conceivable that AI will be used by candidates in ways that serve to bypass campaign finance and elections laws.

We are not arguing that AI will be used as a tool to help beat the system but instead that AI will have a real, and perhaps unpredictable, impact on our democratic systems. It can be used to manage online political operations or to analyze data in order to determine where a candidate should canvass in an effort to maximize their expected vote outcomes. It seems

91 Andre Esteva et al, "Dermatologist-Level Classification of Skin Cancer with Deep Neural Networks" (2017) 542 Nature 115; Daniel Akst, "Computers Turn Medical Sleuths and Identify Skin Cancer," The Wall Street Journal (10 February 2017), online: <https:/www.wsj.com/articles/computers-turn-medicalsleuths-and-identify-skin-cancer-1486740634>.

92 See e.g. Kiran Musunuru, "The Hope and Hype of CRISPR-Cas9 Genome Editing: A Review" (2017) 2:8 JAMA Cardiology 914, online $<$ https://jamanetwork.com/journals/jamacardiology/article-abstract/ 2632329>.

93 C David Naylor et al, "Investing in Canada's Future: Strengthening the Foundations of Canadian Research" (Canada's Fundamental Science Review, 2017), online: <www.sciencereview.ca/eic/site/ 059.nsf/vwapj/ScienceReview_April2017.pdf/\$file/ScienceReview_April2017.pdf>. 
clear that AI could be used to save political campaigns a great deal of money. If it is the case that political campaigns can be run for less, then perhaps Parliaments can, if there is enough political will, drastically improve campaign finance laws by limiting the value of private donations that candidates are allowed to receive. This could have the desirable impact of reducing the private sector's big money influence on elections.

AI technology might also be used in the fight against "fake news" and other attempts to contaminate our democratic processes. Facebook has admitted that attempts were made to flood its social network with false information during the United States' 2016 campaign. ${ }^{95}$ Such attempts to spread false information might become more aggressive and more difficult to detect in the future. AI technology can be leveraged by governments in order to help counter these attempts and to keep democratic processes as safe and free from interference as possible.

Other technologies, like blockchain, may allow our elections to become more efficient by improving online voting systems. ${ }^{96}$ A 2017 paper by the Computational Propaganda Research Project (CPRP) explores some of the ways that AI can potentially be used in the political arena ${ }^{97}$ making it clear that democratic processes and institutions will be impacted. ${ }^{98}$

It is also important to consider the impact AI can have on institutions that are specifically designed to preserve and enhance public trust. The CPRP report explains that bots are being used to make data accessible and hold governments to account via social media. Not only can you now follow Twitter accounts that let you know whenever new government reports are released, ${ }^{99}$ some Twitter bot accounts also report whenever a change is made to a Wikipedia page from a government-owned IP address. ${ }^{100}$ Governments and citizens will be able to use AI in ways that completely transform how our systems of government oversight and accountability function. That being said, we must be proactive in enacting policies that preserve and enhance public trust while also protecting the public and public institutions from being subject to destructive uses of AI. The Guardian (7 September 2017), online: <https://www.theguardian.com/technology/2017/sep/06/ facebook-political-ads-russia-us-election-trump-clinton>. For an explanation of how blockchain works, see e.g. Keith Martin, Everyday Cryptography: Fundamental Principles and Applications, 2nd ed (Oxford: Oxford University Press, 2017). 97 Fenwick McKelvey \& Elizabeth Dubois " "Computational Propaganda in Canada: The Use of Political $<$ blogs.oii.ac.uk/politicalbots/wp-content/uploads/sites/89/2017/06/Comprop-Canada.pdf > .

98 See e.g. Jeff Kao, "More than a Million Pro-Repeal Net Neutrality Comments Were Likely Faked," Hackernoon (23 November 2017), online: <https://hackernoon.com/more-than-a-million-pro-repeal-netneutrality-comments-were-likely-faked-e9f0e3ed36a6> (for an example of how fake accounts can be used to make comments online in an effort to improperly influence policy decision-making).

99 See e.g. the accounts of Canada, Office of the Conflict of Interest and Ethics Commissioner, online: $<$ twitter.com/CIEC_CCIE/> and Ontario, Office of the Integrity Commissioner, online: <twitter. com/ON_Integrity/ $/$, both of which Tweet out links to every new report that they are required to make publicly āvailable.

100 One example, as indicated in the CPRP report, is the Governement of Canada Wikipedia Edits Bot, online: <twitter.com/gccaedits > that Tweets whenever an anonymous edit is made to a Wikipedia page from a government of Canada computer. Heather Ford, Elizabeth Dubois, and Cornelius Puschmann provided several examples to WikiEdits: "Keeping Ottawa Honest - One Tweet at a Time? Politicians, Journalists, Wikipedians, and their Twitter bots" (2016) 10 Intl J Communication 4891 at 4900, online: $<$ comprop.oii.ox.ac.uk/wp-content/uploads/sites/89/2016/10/Fordetal.pdf $>$. 


\section{EnVironmental ANd Agricultural Justice}

Canada's history is in great part one of colonialization and natural resource exploitation. Pulp and paper, petroleum, natural gas, gold, nickel, uranium, and grains such as wheat are among the resources that have driven Canada's economy. This reliance on the environment for the country's prosperity has led to concerns about sustainability and caused the Government of Canada to recognize a need to work to protect the country's biodiversity. ${ }^{101}$ Environmental scientists are doing this important work in part by using AI models to understand how ecosystems might respond to possible disruptions. ${ }^{102}$ This use of AI has huge potential benefits for $\mathrm{Canada}^{103}$ as it works to govern the conservation and sustainable use of its natural resources.

\section{E. National SECURITY}

The North American Aerospace Defence Command (NORAD) has become a topic of controversy under the presidency of Donald Trump. ${ }^{104}$ President Trump made several comments early in his presidency about the need for other countries, especially NATO members, to spend more on defence instead of forcing the US to shoulder the financial burden. Despite the historically strong relationship between the two countries and the generally positive joint statement released by President Trump and Prime Minister Trudeau in February 2017, ${ }^{105}$ it was reported in September 2017 that "[c]urrent US policy directs the American military not to defend Canada if it is targeted in a ballistic missile attack."106

In response to this development, Canada has begun to leverage AI in order to improve its national defence capabilities. In the Arctic, for example, Canada is hoping to deploy autonomous underwater vehicles to patrol and use AI systems that analyze underwater

Canadian Parks Council, One with Nature: A Renewed Approach to Land and Freshwater Conservation in Canada (Ottawa: Canadian Parks Council, 2018), online: <www.conservation2020canada.ca/s/ Pathway-Report-Final-EN-rdnk.pdf> (Canada, the European Community, and 195 other parties convened in 2010 at the Conference of the Parties for the Convention on Biological Diversity and developed a Strategic Plan for Biodiversity. Canada followed up by adopting a suite of national targets in 2015 known as the "2020 Biodiversity Goals and Targets for Canada." Canada Target 1 states: "By 2020, at least 17 percent of terrestrial areas and inland water, and 10 percent of marine and coastal areas, are conserved through networks of protected areas and other effective area-based measures" at 4). See e.g. Kenneth J Bagstad et al, “Artificial Intelligence for Ecosystem Services: A Guide to Models and Data”(The ARIES Consortium, 2011), online: < aries.integratedmodelling.org/wp-content/uploads/2016/ 03/ARIESModelingGuide1.0.pdf>; Peter Kourtz, "Artificial Intelligence: A New Tool for Forest Management" (1990) 20:4 Can J Forest Research 428.

Soumitra Dutta et al, The Global Innovation Index 2017: Innovation Feeding the World, 10th ed, Soumitra Dutta, Bruno Lanvin \& Sacha Wunsch-Vincent, eds (Geneva: World Intellectual Property Organization, 2017) at 14 (The Global Innovation Index provides detailed metrics about the innovation performance of 127 countries and economies around the world in relation to innovation in agriculture and food systems. Canada is ranked 18th on this index, but leveraging AI could help to improve this ranking).

104 See Justin Trudeau, Prime Minister of Canada, Media Release, "Joint Statement from President Donald J. Trump and Prime Minister Justin Trudeau" (13 February 2017), online: <pm.gc.ca/eng/news/2017/ 02/13/joint-statement-president-donald-j-trump-and-prime-minister-justin-trudeau $>$ (this joint statement was released after the leaders' first official meeting and noted: "The North American Aerospace Defense Command (NORAD) illustrates the strength of our mutual commitment. United States and Canadian forces jointly conduct aerospace warning, aerospace control, and maritime warning in defence of North America. We will work to modernize and broaden our NORAD partnership in these key domains, as well as in cyber and space"). Ibid.

106 Lee Berthiaume, "Policy Says U.S. Will Not Defend Canada from Ballistic Missile Attack: General," The Star (14 September 2017), online: <https://www.thestar.com/news/canada/2017/09/14/policy-saysus-will-not-defend-canada-from-ballistic-missile-attack-general.html>. 
sounds in order to guard against intruders in Canadian waters. ${ }^{107}$ Having finite financial resources means that a government like Canada's needs to think creatively about how to fulfill its defence needs. Leveraging AI may be the best option that Canada has if it wishes to improve the self-sufficiency of its national defence strategies. ${ }^{108}$

It is important to note here that we share Kerr's call to the Government of Canada to expressly prohibit AI from being permitted to independently make life-and-death decisions. AI should only be used to assist humans in making decisions related to matters of national defence. We believe that AI must be deployed in order to improve Canada's defence systems, especially because of AI's data analysis capabilities, but we must always remain vigilant in guarding against the possibility that our use of AI leads down a road where algorithms are making autonomous or unvalidated decisions about life and death.

Cybersecurity is another important part of Canada's national security landscape. This was made clear in 2016 when it was widely believed that the Russian government exploited US cybersecurity in order to interfere in that country's election. As Robert Mueller indicated in the Report on the Investigation into Russian Interference in the 2016 Presidential Elections, the GRU (Glavnoje Razvedyvatel'noje Upravlenije) cyber unit "had primary responsibility for hacking the DCCC and DNC, as well as email accounts of individuals affiliated with the Clinton Campaign." ${ }^{109}$ AI systems can perform predictive analyses in order to anticipate cyberattacks. They can even be used to help governments cope with the complexity of cyberspace in order to better support effective decision-making by humans who are responsible for responding to cyberattacks. ${ }^{110}$ There is a clear role for AI in enhancing cybersecurity infrastructure.

\section{F. Internet ACCESS ANd DATa COLlection}

Systems driven by machine learning can only work if they have access to data. Although we need to have deep, meaningful, ongoing conversations about whose data AI systems should have access to, when, why, and for what reasons, the fact is that they do still need access to data. As noted in a 2017 policy paper published by the Internet Society, "AI is an Internet enabled technology." 111 We have already discussed some of these challenges in the context of privacy laws and intellectual property laws, but one of the greatest challenges Canada will face as it seeks to develop its AI economy is to ensure broad and impartial access to the data needed for AI research. It is accordingly becoming more important that Canada seeks to improve Internet access as part of its AI strategy.

Jimmy Thomson, "Canadian Military Developing Surveillance System to Monitor Arctic Waters," $C B C$ News (2 August 2017), online: <www.cbc.ca/news/canada/north/cause-array-drdc-test-1.4232348>.

108 See e.g. Greg Allen \& Taniel Chan, "Artificial Intelligence and National Security" (Harvard Kennedy School Belfer Center for Science and International Affairs, 2017), online: $<$ https://www.belfercenter. org/sites/default/files/files/publication/AI\%20NatSec\%20-\%20final.pdf > (for a study of how AI can be used as part of national defence strategy in the US).

US, Department of Justice, Report on the Investigation into Russian Interference in the 2016 Presidential Election (Washington, DC: DOJ, 2019) at 36-37, online: <www.justice.gov/storage/ report.pdf>.

110 US, Preparing for AI, supra note 29 at 36.

Internet Society, "Artificial Intelligence and Machine Learning: Policy Paper," (April 2017) at 2, online: $<$ https://www.internetsociety.org/wp-content/uploads/2017/08/ISOC-AI-Policy-Paper_2017-0427_0.pdf $>$. 
Unfortunately, cellphone providers in Canada charge among the highest rates in the world. ${ }^{112}$ Fixed broadband rates are also among the highest in the world, ${ }^{113}$ thus making it likely that the data that are legitimately collected through consumer Internet use will be limited in some ways. If Internet access is not affordable to some, for example, then only the data of certain subsets of the population will be collectable and usable in AI systems. This could have very negative long-term implications for already marginalized populations. Canada's problems with expensive Internet access may limit the growth of AI by limiting the availability of balanced, Canada-specific data.

\section{G. LABOUR LosS}

Another huge challenge that the age of AI has given rise to for governments around the world is that of job loss caused by increasing automation. Automation can reduce costs and lead to greater efficiencies and profits for governments and corporations, but those efficiencies and profits generally come at a price. According to a 2017 report from the Brookfield Institute for Innovation + Entrepreneurship at Ryerson University, "[o]verall, 46 percent of work activities in Canada have the potential to be automated, across all industries; this is equivalent to 7.7 million jobs." "114 Part of the cost of job loss is borne by Canada's social welfare system, also known as employment insurance. Automation and AI therefore pose a huge potential challenge for Canada.

Although many jobs will be lost, AI will also create many new jobs. ${ }^{115}$ Some of these jobs will be doing things that we have not yet conceived of. In order to capitalize on this inevitability, Canada needs to begin identifying where these jobs will be and what changes it needs to make in order to be prepared to fill those jobs with Canadian workers. This will require broad-ranging multidisciplinary conversations about the types of opportunities that AI will give rise to. Educators and curriculum designers across Canada must also begin to make changes so that learners at all levels can benefit from educational content and pedagogical approaches that better prepare them to enter into and excel in a new, innovative, and heavily automated workforce.

\section{A Canadian Approach to a Global Challenge}

Canada has signaled its interest in being an AI superpower and must now decide how it wants to regulate the field. It should start by ensuring that foundational policies governing

112 NGL Nordicity Group Ltd, 2016 Price Comparison Study of Telecommunications Services in Canada and Select Foreign Jurisdictions (Ottawa: Canadian Radio-television and Telecommunications Commission, 22 March 2016) at 37-38, online: <https:/crtc.gc.ca/eng/publications/reports/ compar/compar2016.pdf>

113 Ibid at 48-50.

114 Creig Lamb \& Matt Lo, "Automation Across the Nation: Understanding the Potential Impacts of Technological Trends Across Canada" (Brookfield Institute for Innovation + Entrepreneurship, 2017) at 4, online:<https://brookfieldinstitute.ca/wp-content/uploads/2017/09/RP_BrookfieldInstitute_Automa tion-Across-the-Nation.pdf $>$.

115 Bernard Marr, "Instead of Destroying Jobs Artificial Intelligence (AI) Is Creating New Jobs in 4 Out of 5 Companies," Forbes (12 October 2017), online: <https://www.forbes.com/sites/bernardmarr/ 2017/10/12/instead-of-destroying-jobs-artificial-intelligence-ai-is-creating-new-jobs-in-4-out-of-5companies/>. 
liability, transparency, and accountability reflect Canadian values, ${ }^{116}$ such as those found in the Charter of Rights and Freedoms. ${ }^{117}$ Canada can be among the first movers if it acts quickly and can set precedent that sends a signal to the rest of the world that the country is ready for innovation. Rousing international interest can inspire a level of trust in Canada for its willingness to support the industry while also taking on the technology's inherent risks.

\section{A. Building Trust}

Technological innovations should, at least in theory, aim to do something useful for humans. A government's adoption of technology should be no different. What is arguably unique about governments, however, is that they have a moral duty to explain to their citizens what the useful purpose is for which they have adopted a particular technology. This explanation is even more important when a government employs a technological innovation that will replace part of its workforce. If governments adopt AI to deliver standard services to citizens, they should not only offer the public access to a transparent cost-benefit analysis and rationale for their decision to do so, but they should also be transparent about how that AI functions. Some AI systems will use inputted and learned formulae and precedents in order to make value judgments that could potentially have a negative or deleterious effect on citizens (for example, AI could do or say things that violate the Charter). ${ }^{118}$ Governments have a strong moral duty to ensure that they are transparent about AI systems that play a role in the allocation and application of government resources.

If we accept that it is important for government to be accountable to the public about its use of AI, then we have to ask whether transparency is the solution. ${ }^{119}$ Frank Pasquale has aptly noted that "[t]he first step toward accountability is transparency." 120 But what does it mean to be transparent when it comes to AI systems, and who should decide whether transparency is the best way to get to accountability? Perhaps there are situations where something more than transparency is required in order to ensure accountability. These are big questions that governments and AI scholars are beginning to write about.

Governments in Canada will be confronted with difficult decisions about big issues, such as: whether to mandate the use of self-driving vehicles if data demonstrate that they are safer than human-driven vehicles; ${ }^{121}$ whether to terminate workers if their jobs can be performed more efficiently (in terms of cost and quality) by AI; or whether there are exceptions that ought to be made to the general default position that AI algorithms be made transparent. Should a government be able to use AI to help it make those decisions? An AI system might, of course, be better at making decisions than humans are, but it is not the case that being

116 See European Robotics, supra note 34 at 6 (where the importance of values was also espoused by the European Parliament).

117 Canadian Charter of Rights and Freedoms, Part 1 of the Constitution Act, 1982, being Schedule B to the Canada Act 1982 (UK), 1982, c 11 [Charter].

118 See e.g. Veenu Goswami, "Algorithms, Expression and the Charter: A Way Forward for Canadian Courts" (2017) 7:1 Western J Leg Studies 1 (for an interesting analysis of whether AI-generated speech should be protected under section 2(b)).

119 See US, Preparing for AI, supra note 29 at 31 for a discussion of the importance of greater transparency when AI tools are used for public purposes.

120 Frank Pasquale, "Beyond Innovation and Competition: The Need for Qualified Transparency in Internet Intermediaries" (2010) 104:1 Nw UL Rev 105 at 109.

121 See Germany, Strategy, supra note 26 at 9 for a discussion of how road safety has improved as assistive technologies have been adopted in the automotive industry. 
better at making decisions is the same thing as making better decisions. As noted in President Barack Obama's Preparing for AI report, "[t]he use of AI to make consequential decisions about people, often replacing decisions made by human actors and institutions, leads to concerns about how to ensure justice, fairness, and accountability." 122 Nothing less than the public's trust in government is at stake.

\section{B. RESPONSIBLE USE OF AI}

We are only just beginning to understand the many possible uses for AI technology. What commentators all agree on, however, is that technologies are not value-neutral. Algorithms are the building blocks of AI systems and are developed by programmers in order to collect and organize enormous amounts of data. In the case of machine learning, "learning algorithms - not computer programmers — create the rules." 123 A machine learning system can evolve to become increasingly more complex and can move further and further away from its original programming. Regardless of how advanced it becomes, however, every AI system is built off its base programming, which may include the biases of its programmer(s). Furthermore, the data that serve as input for an algorithm may also contain biases.

Much like the recipe for Coca-Cola, algorithms used in a commercial context are proprietary and unlikely to be made public. This means that the public may not even be able to detect the ways in which the technologies they are using are reflecting or perpetuating bias. Pasquale has written about these biases in the context of Internet intermediaries, such as Internet service providers and search engines. He notes, for example, that "Google's secrecy about its website-ranking algorithm is well-known." 24 The challenge of proprietary algorithms is so apparent that some companies are starting to develop codes of conduct for AI use that are reflective of the types of codes of ethical conduct that a human resources department might oversee. ${ }^{125}$ Intel Corporation released a white paper in 2017 that was selfreflective in substance despite being called "The Public Policy Opportunity." "In the white paper, Intel noted that "[ $\mathrm{t}]$ rust in AI requires organizations to demonstrate to the public and government regulating bodies that the technology is designed, implemented, and operated responsibly." 127 There is a clear and broad consensus about the fact that bias must be eliminated from AI systems. Exactly how to accomplish this goal is not so obvious.

Some commentators who are working on the question of how to ensure that we are using AI responsibly have proposed public bodies that could oversee the use of AI in society.

US, Preparing for AI, supra note 29 at 30.

Internet Society, supra note 111 at 4.

Pasquale, supra note 120 at 106.

See e.g. Corinna Machmeier, "SAP’s Guiding Principles for Artificial Intelligence” (SAP, 2018), online: $<$ https://news.sap.com/2018/09/sap-guiding-principles-for-artificial-intelligence/>; IBM, "Everyday Ethics for Artificial Intelligence" (IBM, 2018), online: <https:/www.ibm.com/watson/assets/duo/ pdf/everydayethics.pdf $>$; Sundar Pichai, "AI at Google: Our Principles" (7 June 2018), Google (blog), online: <https://www.blog.google/technology/ai/ai-principles/>. See also Accenture, News Release, "Organizations Are Gearing Up for More Ethical and Responsible Use of Artificial Intelligence, Finds Study" (25 September 2018), online: <https://www.accenture.com/ca-en/company-news-releaseartificial-intelligence-finds-study>; Meredith Whittaker et al, "AI Now Report 2018” (AI Now, 2018), online: <https://ainowinstitute.org/AI_Now_2018 Report.pdf>.

Intel Corporation, "Artificial Intelligence: The Pub̄lic Policy Opportunity" (Intel Corporation, 2017), online: <https://blogs.intel.com/policy/files/2017/10/Intel-Artificial-Intelligence-Public-Policy-WhitePaper-2017.pdf>.

Ibid at 8 . 
Pasquale has recommended the formation of an Internet Intermediary Regulatory Council (IIRC). The IIRC "would research and issue reports on suspect practices at Internet intermediaries, while respecting the intellectual property of the companies it investigated."128 Calo has urged the US to consider whether an independent robotics agency within the federal government might be necessary. ${ }^{129}$ A Federal Robotics Commission (FRC) could "advise on issues at all levels — state and federal, domestic and foreign, civil and criminal — that touch upon the unique aspects of robotics and artificial intelligence and the novel human experiences these technologies generate." ${ }^{, 130}$ It would work to build upon the goals of other agencies that already have related responsibilities with respect to AI governance and oversight.

Another comprehensive proposal by Ben Shneiderman is for an independent oversight body called the National Algorithm Safety Board. The Board would have three major duties: "planning oversight, continuous monitoring by knowledgeable review boards using advanced software, and a retrospective analysis of disasters." "131 Anyone looking to develop and deploy a major new algorithmic system would be required to submit an algorithm impact statement to the Board. These statements would include "[s]tandard questions about who the stakeholders are, and what the impacts might be," which would "ensure that implementers think carefully about potential problems and then propose reasonable solutions." 132 Continuous monitoring would follow the initial approval, and the Board would be expected to undertake a retrospective analysis of any disasters. ${ }^{133}$

It seems to us that Canada's AI governance model will benefit from building off the great work that has already been done, but will of course need to be uniquely Canadian. We propose that Canada build a governance model that incorporates new and leverages existing laws, regulations, social customs, norms and values, institutions, professional codes of conduct, industry standards, and government policies.

\section{OVERSIGHT AND ACCOUNTABILITY}

Canada (and its provinces and territories) should focus on both building and fostering the organic growth of a blended governance model that places AI oversight and accountability at the fore of its efforts. This governance model should include: enhanced education curricula at all levels of the education system, focusing on understanding technology and its social and moral implications; an AI oversight agency that reports to a Minister of the Crown and that oversees the use of AI in society (both the private and public sectors); and an advisory body that reports directly to Parliament, akin to an agent of Parliament, but without investigative

Pasquale, supra note 120 at 168-69 for a discussion about the policies and procedures of a hypothetical regulatory body.

Ryan Calo, "The Case for a Federal Robotics Commission" (Center for Technology Innovation at Brookings, 2014), online: <www.brookings.edu/wp-content/uploads/2014/09/RoboticsCommissionR2 Calo.pdf' [Calo, "Robotics Commission"]. Ibid at 3 .

Ben Shneiderman, "The Dangers of Faulty, Biased, or Malicious Algorithms Requires Independent Oversight" (2016) 113:48 Proceedings National Academy Sciences 13538, online: <https://www.pnas. org/content/113/48/13538.full.pdf $>$.

Ibid. 
or "watchdog" functions. ${ }^{134}$ Although there would be dispute resolution mechanisms built into the agency we are proposing, the court system will also play its usual oversight role when this dedicated infrastructure cannot facilitate a resolution to a dispute.

As we have noted throughout this article, $\mathrm{AI}$ is poised to engage us on every level, from the industrial, to the commercial, to the residential, from private life to public life. The Government of Canada's decision to have CIFAR manage its initial \$125 million funding commitment is a clear recognition of the breadth of AI's potential reach and the limitations of the government's own capacity to reach into all those corners with it. Governments generally govern through ideological and political lenses, but something as big and important as the growth of an AI economy deserves to be championed from a politically neutral center that is focused on dialogue, capacity-building, and consensus. To this end, CIFAR has established what it calls a "Pan-Canadian AI Strategy." 135 This strategy focuses on the technical growth of AI through the "Learning in Machines \& Brains" program and the social understanding of AI's implications and impacts through the "AI \& Society" program. ${ }^{136}$ CIFAR's role is crucial in building the blended model for AI governance that we are proposing.

Our blended model begins with education and capacity-building. Curricula from primary schools through to post-secondary institutions must explore technology and the normative issues that technology can give rise to. This includes conversations about big data, privacy, bias and inclusiveness, access, and so on. We are currently in the middle of a generationdefining awakening about needing to be better at educating our youth about the potential dangers of Internet and social media use. We have moved past our feelings of amazement about the invention of the Internet and are now engaging in deep and meaningful conversations about the implications of how we use it and what we want its future to be. The same must happen with AI, but it must happen earlier in the technology's life cycle. Initiatives like CIFAR's AI and Society program can help to facilitate these conversations by focusing on building dialogues about individual values, community values, and commercial values and the intersections between them. Governments across the country must then build from this work in order to strengthen the education system. We must give Canadians the tools they need in order to think and teach proactively about the moral and social implications of this emerging technology.

Conversations about values also need to be ongoing in our industries and our professions. Best practices and industry standards must evolve in order to ensure that Canadian values are reflected in AI design and use. Engineers who work on AI should be subject to value-driven codes of conduct, and other professions, whether self-regulating or not, should be tasked with reflecting on the impacts that AI may have on their work in order to update their codes of conduct, if necessary. We must not only begin the dialogue about ethics and AI at a relatively early point in our curricula, but we must also ensure that opportunities for ongoing reflection become embedded in our public and private institutions. This will require the commitment of the professions, industry organizations, and private and public sector leadership.

\footnotetext{
134 The only agent of Parliament at the federal level in Canada that does not accept complaints and that provides the best model for what we are proposing here is the Parliamentary Budget Officer. CIFAR, supra note 36 . Ibid.
} 
How we use technology is informed by our values, which are in turn informed by our experiences and our acquired knowledge. Education and private regulation reach into places that governments sometimes cannot and are accordingly fundamental to any AI governance strategy. That being said, government does have an active role to play. The role of government must be intertwined with, but also complementary to and reinforcing of, the work that is being done to generate reflective discourse in the private realm.

To protect the public from AI's potential pitfalls, the government will have to move beyond the silos of its parliamentary system and look for creative and flexible solutions. Our proposal in this regard builds off Shneiderman's work on a National Algorithm Safety Board ${ }^{137}$ and advances the idea of an Agency for Responsible and Ethical AI (AREA). This Agency would be complemented by the creation of a novel advisory body, inspired by a Federal Robotics Commission, ${ }^{138}$ that would report directly to Parliament. The reason for this bifurcated approach is to ensure that an everyday oversight body reports to a Minister of the Crown, which ensures its accountability, and that Parliament also has parallel access to a group of experts without having to convene parliamentary committees in order to summon them. We will explain these two bodies more fully below, but it is important to note upfront that the latter body is only necessary due to the complicated nature of AI and how quickly it is evolving. This advisory body may evolve or may only be needed temporarily.

The proposed Agency's role is one of foresight, oversight, and insight. It will be structured as a typical government agency and will be concerned with monitoring advanced AI that is intended for use in medium- to high-risk applications, both inside and outside of government. Much like Shneiderman's Board, this Agency will: approve algorithms before they can be used in situations and conditions that attach to a certain level of risk (the details of which would have to be decided by policy, such as the Treasury Board of Canada's Algorithmic Impact Assessment policy, discussed above ${ }^{139}$ ); follow up periodically to inspect or audit those algorithms as they are being used "in the wild"; and also be responsible for understanding, reporting on, and helping government and society to learn from any significant AI failures (again, conversations about thresholds would have to be embedded into policy).

The legislation that creates the Agency for Responsible and Ethical AI would set out certain fundamental principles, such as that AI must always serve humans and never move beyond a position where humans are in control of the limits of an AI's outputs. ${ }^{140}$ To the degree that doing so does not infringe on (ideally re-conceptualized) intellectual property protection laws, AREA would be structured so as to be highly transparent in its work. It would manage an online registry, which would include information about the AI that has been approved, who created it, who requested its approval, how it will be used, and so on. There could of course be exceptions to the registration requirement, but those would have to be embedded in policy or regulation. A balance must be struck between facilitating

137 Shneiderman, supra note 131.

138 Calo, "Robotics Commission," supra note 129.

139 Karlin, supra note 87.

140 We are thinking here of the possibility that fully autonomous AI agents could eventually exist. An agency like AREA would be in a position to make a statement about whether full autonomy is acceptable or whether AI creators and designers ought to ensure that such systems always have a back door to allow humans to retain or regain control, if and when necessary. 
innovation and protecting the public. The two are not mutually exclusive whatsoever, but it is conceivable that particular applications of AI may run into this tension.

One way to handle tensions that might arise between the goals of encouraging private sector innovation and protecting the public is to create an advisory body that would report directly to Parliament instead of reporting to a minister. This is a somewhat novel approach that engages the concept of an agent of Parliament, but instead focuses only on what we think of as being an agent's advisory functions. The body would be headed by an Emerging Technology Advisory Commissioner (ETAC), who would be a non-partisan appointment with the approval of the leaders of all the recognized parties. ${ }^{141}$ The Commissioner would be tasked with assembling and leading diverse (cultural, age, race, class, and so on) advisory boards that should at the very least include appointees from civil society, government, the private sector, academia, the general public, and the technical community. These rosters of experts will be consulted by the Commissioner as is necessary on issues that are of interest to the Commissioner or are raised directly by Parliament. Members of the advisory boards will therefore need to be independent, at least to the degree that they do not have conflicts of interest on individual files. As is customary with agents of Parliament, the Commissioner would also be required to file annual reports with the Speaker and should be available to take confidential inquiries from individual Members of Parliament and the executive. Such confidential advice could support informed policy-making.

The Commissioner will proactively engage with the advisory board in order to generate public reports about emerging technologies and related issues. These reports should be aimed at helping parliamentarians and members of the public to understand technical, legal, ethical, and social issues related to emerging technologies such as AI. Parliament will also be able to submit specific inquiries to the Commissioner in the form of directions that are contained within resolutions of the House. ${ }^{142}$ Reports generated in response to inquiries from the House will be tabled with the Speaker, as is typical of reports generated by other agents of Parliament. Inquiries from the House should, at least in theory, be directed to the Commissioner rather infrequently, because the Commissioner will be engaging with advisory committees and publishing reports that stay abreast of emerging issues.

Finally, we contemplate some overlap between AREA and the ETAC with respect to providing advice about and approval of proposed uses of AI by government. The ETAC should be consulted by government when it is considering developing AI that it would use for any purpose that brings with it a level of risk beyond de minimis. ${ }^{143}$ The ETAC would have no power to veto proposals, but government should be required to publish reports from

141 An example of a similarly strong appointment process can easily be found in relation to Ontario's Integrity Commissioner, under section 23(3) of the Members' Integrity Act, 1994, SO 1994, c 38: “[T]he person to be appointed has been selected by unanimous agreement of a panel composed of one member of the Assembly from each recognized party, chaired by the Speaker who is a non-voting member." We would propose that the party leaders agree, but presumably a panel member, as is required in Ontario, would only agree after consulting with their party's leader.

142 See House of Commons, Standing Orders of the House of Commons (April 2016) at Appendix 1, s 27(3) (for an example of how a Commissioner of Parliament can receive directions from the House by way of resolution).

143 Military or defence use of AI could be one exception that the government might want to carve out of this legislative duty to consult. Such an exception should not preclude the ETAC from research in this area nor from publishing general guidelines or reports intended to inform government decision-making in this area. 
both the ETAC and the AREA before deploying a new AI system. Furthermore, as a result of its access to expertise, its reporting obligations to Parliament, and its mandate to stay abreast of emerging trends and issues, the ETAC would be seen as taking on a de facto advisory role to the AREA through its research and annual reports.

As we see it, there are also at least three major impediments to establishing effective AI accountability infrastructures in Canada that must be addressed. The first is the potential lack of experts in the field who would be interested in these oversight and advisory positions. Second is the incredible difficulty in understanding how a machine learning system solves a complicated problem. And the third is the various public sector ethics and accountability laws.

Experts in AI are in high demand. Industry is willing to pay top dollar for new graduates with technical skills. Government cannot compete with the private sector when it comes to salaries. Canada must therefore continue to be fully committed to funding AI research in universities and must also improve public school curricula. For all students, "coursework in STEM, and specifically in areas such as computer science, will likely be especially relevant to work and citizenship in an increasingly AI-driven world." 144 If we do not build up the workforce's computer science literacy and expertise, then we risk not having the public sector human resources that we need in order to oversee the use of AI.

Second, Calo notes that "[m]any AI systems in use or development today are proprietary, and owners of AI systems have inadequate incentives to open them up to scrutiny."145 Oversight can only be effective if those who are responsible for the oversight actually have access to and understand the thing(s) that they are charged with overseeing. Furthermore, even if they are made available to an oversight body, algorithms can do analysis that is too complex for humans to understand. Both access and complexity can lead to challenges for oversight. Access can ideally be dealt with by using legal mechanisms, but education and a purposeful leveraging of technological tools will be the only way to counteract the challenges of complexity. And, in our opinion, there will be situations in which society will have to become just as comfortable with not being able to understand an AI's decision as it is with not being able to understand the decisions that humans make.

Finally, industry is very powerful and will no doubt take advantage of Canada's suboptimal lobbying, campaign finance, and conflict of interest laws. ${ }^{146}$ Good policy that limits what industry can do in these areas could come at a cost for politicians who are looking to raise funds and garner support for re-election. One of the challenges for advancing AI in Canada will be that industry has plenty of money to lobby government on policy issues that matter to it and politicians need donations from the leaders of industry in order to fund their

144 US, AI Automation, supra note 30 at 31.

145 Calo, "AI Policy," supra note 4 at 430.

146 See e.g. Beatrice Britneff, "Enforcement of Lobbying Laws 'in Jeopardy' Without Money to Fight Apotex Suit: Watchdog," ipolitics (1 December 2017), online: <https://ipolitics.ca/2017/12/01/ enforcement-lobbying-laws-jeopardy-without-money-fight-apotex-suit-watchdog $>$ (for one example of how money can be used to put pressure on or get around accountability rules when government is not well-prepared). 
election campaigns. ${ }^{147}$ This may seem cynical, but strong AI policy will either have to be driven by strong public pressure or will have to emerge in spite of what we expect will be tremendous corporate pressure to maintain minimal government oversight over proprietary algorithms. After all, corporations do have a duty to their shareholders and some will interpret this duty as compelling them to lobby against strong regulation.

The Government of Canada's decision to engage CIFAR on the AI file suggests a degree of awareness about the challenges we have outlined above and the government's own inability, or lack of desire, to address them. It is perhaps not surprising then that our proposed AI governance model relies on a multi-faceted, multi-stakeholder approach. Strong and clear governance structures have the ability to promote confidence in Canada's commitment to AI and could be helpful in attracting talent and driving innovation. In order to establish itself as a global leader, Canada's governance strategy must engage everyone who has a stake in the success of AI, including those who have not historically had a seat at the table.

\section{Policy First, Then LAW}

For some commentators, the challenges of AI demand swift legal action to address every possible concern about AI use. We do not believe that this is necessarily the best approach. Although law has a reputation for being a laggard, especially in relation to emerging technology, we know that the Singularity is not looming over us. ${ }^{148}$ We share Calo's opinion that "[i]t may not be wise or even feasible to pass general laws about artificial intelligence at this early stage." 149 Now is the time to recognize that we have incomplete information about how AI will evolve, and to make sure that governments craft flexible policies that help to build the infrastructure needed in order to foster the positive social effects of AI while minimizing its negative impacts. Policies can signal to the public and to industry how the government wants to proceed without the government having to move too quickly. Although policies may eventually map onto laws, they afford greater flexibility in the interim and allow more time for dialogue to take place and consensus to emerge about the best way forward. This policy-first approach will give government the time it needs in order to properly establish, support, and strengthen the blended governance approach that we have proposed above. This is not an appropriate time for knee-jerk reactions.

See e.g. Ian Greene \& David P Shugarman, eds, Honest Politics Now: What Ethical Conduct Means in Canadian Public Life (Toronto: James Lorimer \& Company, 2017) (for excellent overviews of Canada's lobbying, campaign finance, and parliamentary conflict of interest laws, including discussions about the strategies that companies employ in order to influence politicians).

148 Ray Kurzweil, The Singularity Is Near: When Humans Transcend Biology (New York: Penguin, 2005). Kurzweil defines singularity as follows: "a future period during which the pace of technological change will be so rapid, its impact so deep, that human life will be irreversibly transformed" at 3. In a 2016 study, Vincent C Müller and Nick Bostrom surveyed 550 AI experts from different groups (AI philosophers and theorists, technical experts, members of the Greek Association for AI, and top AI authors) and concluded that AI is likely to reach human ability only by 2040-50: Vincent C Müller \& Nick Bostrom, "Future Progress in Artificial Intelligence: A Survey of Expert Opinion" in Vincent C Müller, ed, Fundamental Issues of Artificial Intelligence (Switzerland: Springer International Switzerland, 2016). 


\section{Conclusions}

Research is undoubtedly the foundation of education. We encourage Canadian researchers to dig deep into the varied implications of specific uses and applications of AI. Starting the conversation is important, but merely starting it provides "little to help practitioners in navigating daily ethical problems in practice or in diagnosing ethical harms, and do[es] little to directly change ethics in the design and use of AI." ${ }^{150} \mathrm{We}$ must therefore turn our collective attention to the direct and actionable challenges that AI gives rise to. ${ }^{151}$ Focusing efforts at the micro level will help Canada to drive the conversation and establish itself as a thought leader, not just an innovation hotbed.

We must also challenge our governments to act decisively, yet flexibly, in order to prepare for the possibility that AI innovation may evolve in ways that we had not previously contemplated. After all, Canada is far from being the only country that is excited about AI. Even if we think that we are preparing properly for what AI will look like in the future, we may be completely wrong. The blockchain, for example, may play a much more important role in AI's long-term development and democratization than we currently understand it to have.

This article has drawn attention to some of the most glaring challenges and opportunities that lie ahead for Canada and has cautioned against moving forward with too much rigidity. We have proposed a blended governance approach that never loses sight of the importance of public discourse and engagement, but that is equally as attentive to the need for strong oversight and accountability. This approach allows us to constantly engage in knowledge generation, evaluation, and dissemination in a way that can inform public policy and, ultimately, our legal structures. AI has captured the world's imagination unlike any technological innovation since the emergence of the Internet. It is not enough to sit and watch it with amazement, though: we must stand up and carve out a clear path to guide its way forward. 
[this page is intentionally blank] 